CUADERNOS DE ESTUDIOS GALLEGOS, LIX Núm. 125 (enero-diciembre 2012), págs. 259-272

ISSN: $0210-847 \mathrm{X}$

DOI: 10.3989/ceg.2012.125.11

\title{
LA MEMORIA Y LA HISTORIA MEDIEVALES COMO REALIDADES INDISOCIABLES
}

ISRAEL SANMARTÍN

Universidad de Santiago de Compostela 


\title{
LA MEMORIA Y LA HISTORIA MEDIEVALES COMO REALIDADES INDISOCIABLES
}

\author{
RESUMEN \\ En el presente trabajo estudiaremos las relaciones entre historia y memoria medievales. Para ello \\ recurriremos a un análisis historiográfico, histórico y conceptual de ambos términos. La conclusión \\ es la imposibilidad de separar ambos conceptos y la importancia del historiador con su subjetividad \\ y su trabajo para mantener ese equilibrio. \\ PALABRAS CLAVE: memoria, historia, historiografía, medieval, presente.
}

\section{A MEMORIA E A HISTORIA MEDIEVAIS COMO REALIDADES INDISOCIABLES}

\section{RESUMO}

No presente traballo estudaremos as relacións entre historia e memoria medievais. Para iso recorreremos a unha análise historiográfica, histórica e conceptual de ambos os dous termos. A conclusión é a imposibilidade de separar ambos os dous conceptos e a importancia do historiador coa súa subxectividade e o seu traballo para manter ese equilibrio.

PALABRAS CLAVE: memoria, historia, historiografía, medieval, presente.

\section{MEMORY AND MEDIEVAL HISTORY AS INSEPARABLE REALITIES}

\begin{abstract}
In this paper, we study the relations between medieval history and medieval memory. We will do a historiographical historical and conceptual analysis. The conclusion is that it is impossible to separate history and memory. Also, The historians are important in this balance with his subjectivity and his work.
\end{abstract}

KEY WORDS: memory, history, historiography, medieval, present. 
Recibido/Received: 01/07/2012

Aceptado/Accepted: 14/08/2012

$\mathrm{M}$

emoria e historia; historia y memoria, son dos términos de moda en boca de académicos y políticos. En el presente trabajo estudiamos la capacidad del presente para reelaborar las memorias y hacer presente lo ausente (individual y colectivamente). Trataremos de entender cómo trabaja el presente con las memorias. A éstas las definiremos, las estudiaremos historiográficamente y buscaremos los vínculos, similitudes y diferencias entre las memorias y las historias, para concluir en su indisociabilidad. El mundo medieval es el laboratorio perfecto para comprobar las uniones y los puentes que unen a la historia con la memoria (individual y colectiva). La disociación de historia y memoria como la diada objetivo-subjetivo o científico-no científico no tiene sentido. La historia y la memoria están imbricadas de tal forma que las historias se convierten en memorias y viceversa. Esta cuestión está muy clara en la historiografía medieval, como por ejemplo en las crónicas nacionales donde las memorias y las historias se confunden y se entienden de forma conjunta, gracias a la labor del propio historiador (o cronista). Comencemos entonces a trabajar.

\section{EL PRESENTE MEDIEVAL COMO CONSTRUCTOR DE MEMORIAS}

La reflexión por la historia del propio tiempo o del tiempo vivido es algo constitutivo de la historiografía desde sus orígenes puesto que responde a la capacidad de la historia de narrar las memorias del pasado. Las estructuras de la historiografía reflejan el tiempo de las sociedades a las que pertenece. Cuando el presente estacionario ha dejado de ser el eje de la narración histórica se ha podido abrir la moderna disciplina histórica con la división de la historia en épocas. Por ejemplo, en la época medieval es evidente que no existe una historia inmediata tal y como la entendemos hoy en día pero sí que hay una preocupación por la historia de su tiempo puesto que la historiografía medieval concedió importancia a los hechos cercanos, y a las memorias correspondientes a la generación 
de los cronistas y sus precedentes orales, escritos y escuchados ${ }^{1}$. La historia de la Edad media es eclesiástica, pero su resultado no es uniforme, homogéneo y monótono porque dependió más de los autores que de la concepción dominante. En este sentido, los historiadores comprendían esencialmente los acontecimientos principales del pasado y de los años en que ellos vivieron ${ }^{2}$.

Por tanto, todos somos hombres de nuestro tiempo condicionados por el pasado que siempre permanece, por ese pasado individual o colectivo. Los cronistas en la Edad Media habían vivido más el presente que el pasado y querían conservar para la posteridad el recuerdo de los acontecimientos vividos y los pasados $^{3}$. La Edad Media creó modelos historiográficos propios más allá de adaptar los ya existentes al cristianismo y la concepción escatológica, mediante historias, crónicas, anales, etc. El mismo Le Goff declaraba que el presente es fundamental en el estudio de la Edad Media 4 .

La idea de presente está presente tanto en la Edad Media como en la Antigua o en la Moderna, pero no fue hasta los años 60-70 del siglo XX cuando se puso encima de la mesa la cuestión del presente en la época contemporánea. Una situación que ha vuelto a variar desde los años 90 con la aparición de nueva documentación y nuevos formatos visuales, orales, electrónicos, etc., asociados en buena medida a las discusiones sobre la memoria histórica ${ }^{5}$ y al concepto de generación 6 .

En la Edad Media, la cultura era principalmente memorial porque el cristianismo mismo lo era. En general, la Edad Media hereda gran parte de la problemática clásica sobre la memoria aunque tiene sus propias aportaciones. En San Agustín la memoria pasa a interiorizarse, a pasar de lo público a lo individual. Se realiza una adaptación de la tradición griega sobre el particular. Acoge la heren-

\footnotetext{
${ }^{1}$ Ver Bernard GuEnÉe, Le Métier d'historien au Moyen Age: etudes sur l'historiographie medievale, Paris, La Sorbonne, 1977.

${ }^{2}$ Como han señalado algunos autores, no es del todo correcto afirmar que la Edad Media no llegó a crear modelos historiográficos propios. Ver Carmen OrCÁsTEGUI y Esteban SARASA, La historia en la Edad Media, Madrid, Cátedra, 1991.

3 Ver Jose E. Ruiz Domenech, La memoria de los feudales, Barcelona, Argot, 1984.

4 Jacques Le Goff, "La vision des autres: un médiéviste face au temps présent" en Questions à l'histoire des temps presents, Paris, Éd. Complexe, 1992, págs. 99-109.

${ }^{5}$ Entendiendo la memoria en relación con la historia (Hartog) y la memoria en sí misma como algo activo. Ver François HaRTog, Régimes d'historicité: présentisme et expériences du temps, París, Éd. du Seuil, 2003 y ver el desarrollo del concepto "memoria histórica activa" de la Red Internacional de historiadores "Historia a Debate" [en línea], disponible en http://www.h-debate.com/Spanish/ historia\%20inmediata/memoria/menu.htm [Consulta: 30 de septiembre de 2010].

${ }^{6}$ Entendido más como generación epistémica que como generación biológica. Ver Claudio CANAPARo, Ciencia y Escritura, Buenos Aires, Zibaldone, 2003 e Imaginación, mapas, escritura, Buenos Aires, Zibaldone, 2000.
} 
cia del ars memoriae y la Retórica Clásica refiriéndose tanto a la memoria como a las imágenes ${ }^{7}$. Para San Agustín la memoria incluye una cierta actualización y construcción de la memoria. El arte de la memoria, incluido en muchos tratados escolares, fue considerado hasta la época moderna como fundamento de la formación intelectual. Marciano Capella, Alcuino, Bocompagno son ejemplos de esto, donde la memoria aparece escorada hacia la cimentación de la piedad religiosa. La buena memoria adquiere la consideración de síntoma de superioridad moral e incluso se consideraba un elemento central del conocimiento bien para la rememoración al estilo platónico o bien como agente constitutivo de la experiencia a la manera aristotélica. La Edad Media veneraba a los ancianos como hombres-memoria, a la literatura juglaresca, lirica o épica y hunde sus raíces en las formas de transmisión no escritas ${ }^{8}$.

No es fácil generalizar sobre la memoria social en una época cronológicamente tan dilatada. Se puede hablar de memorias locales que compartían ciertos elementos ideológicos y actitudes. Los poderes desarrollaron sus propias pedagogías de la memoria para ilustrar y transmitir determinados valores o legitimar su preponderancia política o espiritual, como la historia litúrgica, las fiestas, las conmemoraciones de santos, las conmemoraciones de grandes personajes como Carlomagno o las colectividades judías. Según los expertos, muchos autores medievales vivían en una cultura que no puede calificarse propiamente de oral y sin embargo consideraban la memoria un elemento central del conocimiento, bien para la rememoración bien para el paso de los acontecimientos a la historia9

Lo que revolucionará la memoria será la aparición de la imprenta en el sentido de que cambia la relación entre la oralidad y lo escrito ${ }^{10}$, y también por la actitud reverencial hacia el pasado ${ }^{11}$. La memoria influye decisivamente en la producción, recepción y creación de textos y manuscritos. La memoria en la Edad Media se puede estudiar desde diferentes perspectivas como historiografía, genealogía, liturgia, para crear una imagen de pasado. También se puede entender la memoria como aparece en la psicología medieval así como en la

\footnotetext{
7 Jacques Le Goff, El orden de la memoria. El tiempo como imaginario, Barcelona, Paidós, 2004.

${ }^{8}$ Francisco ERICE, Guerras de la memoria y fantasmas del pasado. Usos y abusos de la memoria colectiva, Oviedo, Eikasia, 2009, págs. 28-29.

${ }^{9}$ Mary CArruthers, Le livre de la Mémoire. La mémoire dans la culture medievales, París, Macula, 2002.

10 J. LE Goff, El orden de la memoria...

${ }^{11}$ Aunque muchos autores señalan que no es hasta el siglo XVIII cuando se da el salto en el que se empieza a concebir el pasado como un dominio esencialmente distinto del presente. Las revoluciones liberal-burguesas inauguraron prácticas conmemorativas y políticas de memoria de dimensiones nuevas, así como un recurso legitimador hacia la historia por parte de los nuevos estados nacionales. Ver F. ERICE, Guerras de la memoria..., págs. 29-31.
} 
filosofía y teología. En otro sentido, tenemos ejemplos de textos medievales que fueron transformados en imágenes para que pudieran ser memorizadas más fácilmente ${ }^{12}$.

La memoria juega un papel esencial en los mecanismos que conforman una sociedad. La memoria no se puede dar sin la existencia, conservación y almacenamiento de recuerdos reales y de un proceso mental que permite actualizarlos y objetivarlos. Los hombres de la Edad Media sintieron la necesidad de escribir lo que veían, las hazañas y los valores del pasado. Un impulso que los llevó a construir la historia en base a memorias individuales y colectivas, llegando a la memoria de su familia de su casa, de su linaje. La memoria medieval, como la contemporánea, dirige sus pasos hacia una construcción activa, presente, de lo pensado y del pasado. En buena medida, la memoria medieval es una actividad social, que modifica (recrea, imagina, "empiriza") una realidad mediante un proceso psicológico individual o colectivo. La memoria es una construcción subjetiva y objetiva, discontinua y continua, de recuerdos y olvidos, conscientes e inconscientes. Es un objeto fundamental del saber histórico ${ }^{13}$ donde cabe lo imaginado, lo vivido, lo escuchado, lo contado y lo rememorado ${ }^{14}$.

Domenec, nos habla de una memoria de los feudales en un mundo que fue real en un determinado momento y nos habla de una colisión entre la memoria y la historia a partir de mediados de la octava década del siglo XI. Habla de la decisión de la iglesia de hacer la historia en forma de Anales. La historia sería en estos años escatología inspirada en las Sagradas Escrituras. La historia es algo divino, la memoria algo humano. Por eso los monjes traspasaron los límites e introdujeron narraciones políticas. La relación entre el mundo y la verdad queda rota en beneficio del proceso ideológico ${ }^{15}$. Para Domenec en el siglo XII la sociedad europea occidental fijó dos planos de fijación de los recuerdos, la memoria y la historia. Las relaciones entre ambos distaron mucho de ser armoniosas, sino que se mantuvieron distantes e independientes. La memoria miraba con recelo a la historia y viceversa.

La memoria de los hombres feudales buscó la independencia de criterio con respecto al mundo eclesiástico. La memoria dinamizó el pensamiento de los laicos buscó unos orígenes legítimos y los resituó históricamente. La memoria

12 Susanne RischpleR, "Le coeur voyant. Mémoriser les Sentences de Pierre Lombard” en Frank Willaert, Herman Braet, Thom Mertens and Theo Venckleer, Medieval Memory. Image and Text, Turnhout, Brepols, 2004, págs. 3-41.

13 J. E. Ruiz Domenech, La memoria de los feudales..., pág. 24.

${ }^{14}$ Sobre la construcción de los grandes hombres feudales y de cómo influyen las memorias en las genealogías y parentescos, podemos recurrir a J. E. Ruzz Domenech, La memoria de los feudales...

15 J. E. Ruiz Domenech, La memoria de los feudales..., pág. 27. 
confirmó un modelo social basado en la defensa del territorio, coadyuvó para reunir recuerdos de un linaje en relación a un individuo determinado. Se ejercitó la memoria con el fin de afianzar sus privilegios sociales y políticos hasta el punto de que consiguieron legitimarse como el grupo dominante. Por tanto, podemos hablar de la aparición de la memoria al primer plano histórico. Las narraciones de esos años sirven para legitimar el estatus del individuo que cuenta historias o del aristócrata que encarga el relato. El objetivo es la actualización de la persona como individuo y el objetivo es presentarse a la sociedad con un futuro mejor que el presente y recordando el pasado ${ }^{16}$.

La memoria no sólo habla de actualización del pensar sino de la reactualización del pensar ligado a algo real en y por sí mismo. El carácter de actualización de la memoria consistió en presentar las cosas pasadas dentro de un orden universal. Los que recrean recuerdos no son los reyes ni los aristócratas sino los escritores de profesión, intelectuales laicos (aunque también había los eclesiásticos).

\section{LAS MEMORIAS MEDIEVALES}

La historia se basó en los mitos, religiones y utopías. Eso provocó un enfrentamiento entre el tiempo natural y la percepción de la duración registrada por los hombres, la memoria personal y colectiva que debe hacer sus cuentas con el calendario. El concepto de memoria, como capacidad de conservar informaciones, es ante todo una actividad psíquica en la que el individuo actualiza impresiones o informaciones pasadas o que se imagina como pretéritas ${ }^{17}$. Así, como señala Le Goff ${ }^{18}$, el estudio de la memoria nos lleva a la psicología, parapsicología neurofisiología, biología y la psiquiatría. En ese ámbito también está la memoria histórica y la memoria social:

El proceso de la memoria en el hombre hace intervenir no sólo la preparación de recorridos, sino también la relectura de tales recorridos...Los procesos de relectura pueden hacer intervenir centros nerviosos complicadísimos y gran parte de la corteza cerebral ${ }^{19}$.

\footnotetext{
16 J. E. Ruiz Domenech, La memoria de los feudales..., págs. 40-110.

17 Ver Douglas J Herrmann, et al. (ed.), Memory improvement. Implications for Memory Theory, New York, Springer-Verlag, 1992 y Robert KAIL and Norman E. SPEAR (ed.), Comparative perspectivas on the development of Memory, Hillsdale (New Jersey), LEA, 1984.

18 Ver Jacques Le Goff, Histoire et mémoire, Paris, Gallimard, 1977.

19 J. LE Goff, El orden de la memoria..., pág. 132.
} 
Todo el debate sobre la memoria está relacionado con la memoria colectiva, también denominada, para algunos, memoria histórica ${ }^{20}$. La rememoración aparece plagada de conflictos y controversias. La memoria puede ser invocada como un recurso de los vencidos y los postergados por la historia, pero también se usa al servicio de los vencedores, las clases dominantes o los Estados que utilizan el recuerdo del pasado para difundir sus valores y propagar su visión de la sociedad ${ }^{21}$. Los problemas relacionados con la memoria colectiva tiene una dimensión académica (científica) y mundana (cívico-político). Aperturas de nuevos campos temáticos con el desarrollo de subdisciplinas y enfoques como la historia oral, la historia del tiempo presente, la biografía, etc..

Historiar la memoria es tener en cuenta que el pasado se puede reinterpretar, algo que sucede constantemente en la historia. Existen diferentes tipos de memoria, fundamental la individual y la colectiva. Esta última, la memoria colectiva, es pública. Hay un uso público de las memorias que está sometido a las hegemonías ideológicas y a la propia elaboración del historiador. No es ningún secreto el pensar que las memorias tienen una dimensión de conflicto político, judicial e historiográfico. En ese sentido, podemos establecer ciertos vínculos entre la memoria con la Historia a través del concepto de memoria colectiva de Holbwachs. Los acontecimientos afectan a la historia que sucede y la memoria es la historia vivida y no heredada, tenida en cuenta a partir del concepto de las generaciones: hay una generación apropiada y otra vivida ${ }^{22}$.

\subsection{LA CUESTIÓN HISTORIOGRÁFICA}

Historiográficamente, en relación al concepto de memoria, en el año 1974 todavía no aparecía en los libros Hacer la Historia de Le Goff y Pierre Nora. En cierto sentido, era una consecuencia de esa desconfianza tradicional de los historiadores hacia la memoria. Unos años después, en 1978 en esos volúmenes de la Nueva Historia ya aparece el término "Memoria colectiva". Allí se explica la importancia de las memorias (lugares simbólicos), el pensamiento social y la memoria colectiva, término que se debe a Maurice Halbwachs en su libro Memoria colectiva, donde divide memoria e historia. La historia es "una" pero las memorias colectivas varias. El concepto de memoria colectiva surge en

\footnotetext{
20 Ver Santiago Juan-Navarro y Joan Torres-Pou (eds.), Memoria histórica, género e interdisciplinaridad, Madrid, Biblioteca Nueva, 2008; Mario CARretero, Documentos de identidad. La construcción de la memoria histórica en un mundo global, Buenos Aires, Paidós, 2007; Francesc Álvaro, Memoria histórica, entre la ideología y la justicia, Barcelona, Inehca, 2007; Sisinio PÉrEZ Garzón y Eduardo Manzano Moreno, Memoria histórica, Madrid, Catarata, 2010.

21 F. ERICE, Guerras de la memoria..., págs. 7-8.

22 Ver F. HARTOG, Régimes de historicité...
} 
la década de los 20 con Halbwachs que recoge aportaciones de la filosofía de Bergson, el psicoanálisis o la sociología francesa del siglo XIX. Eso después se ha desarrollado en el siglo XX bajo los condicionamientos sociales del recuerdo, el papel activo de la memoria y los procesos de distorsión de la misma, los usos del pasado en el presente, etc. El historiador es excluido de la memoria en estos inicios historiográficos del término

En 1978 Pierre Nora hablaba de los "lugares de la memoria"23 para colocarse entre la memoria y la historia, en la idea de no oponerlas pero tampoco confundirlas, servirse de una y de la otra. Recurrir a la memoria para ensanchar el campo de la historia. Así surge la historia de la memoria. Se puede decir que la memoria está relacionada con la individualización, la psicologización social y con los lugares. Y también se puede apuntar que la memoria sirve para la reminiscencia de las vivencias en forma presente y como soporte de lo histórico en oral. En esta concepción, las memorias y las historias son separables. No hay historia sin memoria pero son autónomas.

Como decíamos más arriba, a fines del XIX y principios del XX se empieza a elaborar el concepto de memoria colectiva, principalmente por Halbwachs. Así surge el interés por la conciencia, el inconsciente, el tiempo y la duración. Destacan en ese momento los trabajos de Freud, Bergson, especialmente Matière et Mémoire, donde expresa las ideas de memoria-recuerdo, memoria-hábito, inconsciente y olvido, posteriormente sería Durkheim (y alguno de sus discípulos como Mauss) quien abordaría los conceptos de conciencia individual y colectiva, tan próxima a la historia de las mentalidades. La influencia de la Psicología Social (Blondel) y la sociología-antropología (Durkheim, Halbwachs, Mauss, etc.) son patentes en los orígenes de la revista Annales. Halbachws es el fundador de la sociología de la memoria y quien acuña el concepto de memoria colectiva $^{24}$. Aquí se muestra como la sociedad separa de la memoria lo que podría separar a los individuos. La sociedad y sus instituciones tienen que edificarse sobre creencias colectivas que son retradiciones, recuerdos colectivos pero también convenciones que resultan del conocimiento del presente. El pensamiento social es básicamente una memoria. Halbwachs incide en el carácter social de la memoria. Para él, los recuerdos individuales se ubican en marcos colectivos, en una "memoria colectiva" que reconstruye una imagen del pasado acorde con cada época y en sintonía con los pensamientos dominantes de la sociedad ${ }^{25}$. Hay que tener en cuenta los usos sociales de esa memoria. Halbwachs señala que la

\footnotetext{
23 Ver la serie de Pierre Nora sobre Les lieux de mémoire en Gallimard.

24 Maurice Halbwachs, Les cadres sociaux de la mémoire, Paris, Librairie Félix Alcan, 1925.

25 Maurice Halbwachs, La memoria colectiva, Zaragoza, Universidad de Zaragoza, 2004 y Los marcos sociales de la memoria, Barcelona, Anthropos, 2004.
} 
memoria colectiva se distingue de la historia en que no busca el rigor y que los recuerdos que se alimentan de la conmemoración, la adoración, las ceremonias, las procesiones y fiestas pretenden alimentar otras circunstancias. Recordar sería reforzar el vínculo social. Para él existen varias memorias colectivas asociadas a diferentes grupos de pertenencia y sin embargo existe una sola historia.

Después de esto, y sólo puntualmente a Marc Bloch, no interesará más el término memoria colectiva hasta la tercera generación de los Annales, quizá por su interés en las mentalidades. Será en la figura de Pierre Nora ${ }^{26}$, quien retomará todos estos debates desde una separación entre historia y memoria para después buscar posibles vínculos.

Desde las corrientes postmodernas se pone en cuestión esa diferenciación entre historia y memoria, con la apertura de todo esto hacia el lenguaje y el discurso llegando a convertirse la memoria en un discurso que reemplazaría a la historia. Estos debates se dan bajo la presencia de los tres grandes giros operados en los últimas décadas, el lingüístico, el hermenéutico y el subjetivo ${ }^{27}$. En las últimas décadas todo se ha centrado en la nueva historia oral, en los llamados "lugares de la memoria" franceses (Pierre Nora) y en la relación de acontecimientos notables y traumáticos de las sociedades o identitarios.

\section{CONCLUSIÓN}

En ámbitos no académicos se suele confundir historia y memoria. Para estudiarlas hubo primero que disociar ambos planos para luego recuperar sus interrelaciones. Es evidente que hay críticas hacia los historiadores profesionales en el sentido que colaboran en la ocultación cómplice de determinados aspectos del pasado. No es ningún secreto en ese sentido que el historiador es un sujeto humano y como tal actúa en sus investigaciones. La memoria sería la vida vinculada al recuerdo y a la amnesia y vulnerable, sería algo siempre presente. $\mathrm{Su}$ contenido tendría que ver con los recuerdos. La historia, por el contrario, sería una reconstrucción del pasado resultado de una operación intelectual y crítica. Para Nora la memoria brotaría de un grupo al que proporciona cohesión y hay tantas memorias como grupos. La historia, por su parte, sería una y universal y objetiva. La memoria se enraizaría en lo concreto, en el espacio, en el gesto, la imagen y el objeto y la historia no se ata más que las continuidades temporales.

La historia implicaría mantener una posición exterior a los acontecimientos mientas que la memoria se ubicaría en el interior de los mismos. "El objetivo

\footnotetext{
${ }^{26}$ Pierre Nora (dir.), Les Lieux de Mémoire, París, Gallimard, 1997.

27 Ver F. ERICE, Guerras de la memoria..., págs. 55-58
} 
de la historia sería la verdad y el de la memoria la fidelidad"28. Así se establecen tres relaciones posibles entre historia y memoria: la memoria como fuente para la historia, la memoria como objeto de estudio para los historiadores y el papel de la investigación histórica para corregir memorias equivocadas o falsas.

Pero también existen diferentes concepciones de esta relación. Por ejemplo, en los medios de comunicación historia y memoria mantienen relaciones "osmóticas" 29. La memoria asimila los contenidos, informaciones y resultados de la investigación histórica, mientras que esta se alimenta de testimonios y recuerdos. Donde se da mejor eso es en la historia de presente en la que historia y memoria se convierten en tender puentes entre pasado, presente y futuro. Por ejemplo las historias nacionales tienen una configuración fundamental para la configuración de memorias y de legitimación identitaria, es un vector de la memoria junto con la conmemoración, la creación literaria y artística. Enzo Traverso señala que los recuerdos son continuamente elaborados por una memoria escrita en el espacio público, sometidos a modos de pensar colectivos pero influidos por paradigmas científicos, así como habla del papel fundamental de la memoria con respeto a la historia ${ }^{30}$.

En nuestro tiempo también la memoria individual y colectiva se presenta, en algunas ocasiones, como algo más auténtico que la historia, que es algo como una memoria muerta, el "frío producto del positivismo de la ilustración"31. Entre los que más han defendido esta idea está Paul Ricoeur ${ }^{32}$, que defiende la continuidad entre historia y memoria y que diferencia la imaginación, orientada a la ficción o la fantasía, de la memoria, que para él requiere fidelidad. La memoria también pertenece al pasado con lo que el análisis de la memoria y el tiempo se superponen, siendo ésta la última la matriz de la historia, y constituyendo el "testimonio" la transición entre historia y memoria.

El nuevo paradigma historiográfico obliga a replantear el tema. Dosse señala que es un falso dilema el de la historia como verdad y la memoria como fidelidad. La nueva postura sería de buscar una conjunción de fidelidades múltiples a la prueba de la verdad expresadas por una historia social de la memoria. "Al primer movimiento que asegura la primacía de la mirada crítica, el distanciamiento, la objetivación y la desmitologización, sigue un segundo momento, complementario, sin el cual la historia sería puro exotismo: el de una recuperación del

\footnotetext{
28 Ver F. ERICE, Guerras de la memoria..., pág. 78.

29 Ver F. ERICE, Guerras de la memoria..., pág. 79

30 Enzo Traverso, El pasado, instrucciones de uso. Historia, memoria, política, Madrid, Marcial Pons, 2007.

31 Ver F. ERICE, Guerras de la memoria..., pág. 79.

32 Paul Ricoeur, La memoria, la historia, el olvido, Madrid, Trotta, 2003.
} 
sentido que apunta a la apropiación de las distintas sedimentaciones de sentido legadas por las generaciones precedentes, y de las posibilidades no verificadas que tapizan el pasado de los vencidos y los mudos de la historia”, escribe Dos$\mathrm{se}^{33}$, quien afirma que frente al experto historiador que privilegia la verdad y deja a la memoria la función de la fidelidad podemos preguntarnos qué valor tendrían una verdad sin fidelidad y una fidelidad sin verdad. Para articular ambas tenemos que recurrir al relato ya que la historia y la memoria son un modo de selección en el pasado, una construcción intelectual.

Con el tiempo se han ido desarrollando puentes entre historia y memoria. Las dos se necesitan mutuamente. La historia necesita de la memoria porque está vinculada a ella puesto que forman parte del legado individual y colectivo que manejan los propios historiadores. En el mismo sentido, la memoria necesita de la historia para que pueda ser abordada con una metodología y un rigor epistémico. Por lo tanto, es complicada su separación, puesto que están profundamente relacionadas. Y más si las consideramos en el presente, cuando se están activando, reactivando, olvidando y recordando a cada instante en estos tiempos que vivimos de aceleración histórica. Nos encontramos ante una memoria histórica activa $^{34}$. La lucha por la memoria es también, por tanto, una lucha historiográfica. Se puede preservar la memoria y también la historia, pero con el arbitrio de la historiografía ${ }^{35}$. La memoria es un valor social y cultural, y es redundancia de un pasado que se quiere impedir que pase. La historia es todo eso aplicado a una actividad científica, con lo que es un discurso objetivizado sujeto a un método.

No hay memorias inocentes, memorias colectivas vinculadas a un nosotros, pero tampoco hay historias objetivadas, sin presencias subjetivas (y memorias) ${ }^{36}$. La historia ve los acontecimientos desde fuera y desde dentro, por eso se asocia a la memoria. Conservar la memoria está íntimamente relacionado a la construcción de la historia, aunque, claro, la memoria puede historizarse ${ }^{37}$. La memoria es tanto una fuente como parte de la historia. La historia puede restituir la memoria del pasado pero puede rectificarla porque la memoria retiene el pasado pero la historia es la que la explica. La historia es compleja y siempre se está reelaborando como la memoria ${ }^{38}$.

\footnotetext{
33 François Dosse, La historia: conceptos y escrituras, Buenos Aires, Nueva Visión, 2004, pp $217-$ 218, citado en F. ERICE, Guerras de la memoria..., pág. 81.

34 Ver conferencia de Carlos Barros en Montevideo en el año 2007 al respecto en www.h-debate. com.

35 Ver Pierre VILaR, Memoria, historia e historiadores, Valencia, Universidad de Valencia, 2004.

36 Ver Tzvetan Todorov, La memoria, ¿un remedio contra el mal?, Barcelona, Arcadia, 2009.

37 Para mayor profundidad, ver Ricoeur, Paul, La memoria...

38 Jon A. Fernández de Larrea y José R. Díaz de Durana, Memoria e historia. Utilización política en la Corona de Castilla al final de la Edad Media, Madrid, Sílez, 2010.
} 


\section{BIBLIOGRAFÍA}

Álvaro, Francesc, Memoria histórica, entre la ideología y la justicia, Barcelona, Inehca, 2007.

Canaparo, Claudio, Imaginación, mapas, escritura, Buenos Aires, Zibaldone, 2000.

Canaparo, Claudio, Ciencia y Escritura, Buenos Aires, Zibaldone, 2003.

Carretero, Mario, Documentos de identidad. La construcción de la memoria histórica en un mundo global, Buenos Aires, Paidós, 2007.

Carruthers, Mary, Le livre de la Mémoire. La mémoire dans la culture medievales, París, Macula, 2002.

Dosse, François, La historia: conceptos y escrituras, Buenos Aires, Nueva Visión, 2004.

Erice, Francisco, Guerras de la memoria y fantasmas del pasado. Usos y abusos de la memoria colectiva, Oviedo, Eikasia, 2009.

Fernández de Larrea, Jon A. y Díaz de Durana, José R., Memoria e historia. Utilización política en la Corona de Castilla al final de la Edad Media, Madrid, Sílez, 2010.

Guenée, Bernard, Le Métier d'historien au Moyen Age: etudes sur l'historiographie medievale, Paris, La Sorbonne, 1977.

Kail, Robert; Spear, Norman E. (ed.), Comparative perspectivas on the development of Memory, Hillsdale (New Jersey), LEA, 1984.

Halbwachs, Maurice, Les cadres sociaux de la mémoire, Paris, Librairie Félix Alcan, 1925.

Halbwachs, Maurice, La memoria colectiva, Zaragoza, Universidad de Zaragoza, 2004.

Halbwachs, Maurice, Los marcos sociales de la memoria, Barcelona, Anthropos, 2004.

Hartog, François, Régimes d'historicité: présentisme et expériences du temps, París, Éd. du Seuil, 2003.

Herrmann, Douglas J., et al. (ed.), Memory improvement. Implications for Memory Theory, New York, Springer-Verlag, 1992.

Juan-Navarro, Santiago y Torres-Pou, Joan (eds.), Memoria histórica, género e interdisciplinaridad, Madrid, Biblioteca Nueva, 2008.

Le Goff, Jacques, Histoire et mémoire, Paris, Gallimard, 1977.

Le Goff, Jacques, "La vision des autres: un médiéviste face au temps présent" en Questions à l'histoire des temps presents, Paris, Éd. Complexe, 1992, págs. 99-109.

Le Goff, Jacques, El orden de la memoria. El tiempo como imaginario, Barcelona, Paidós, 2004.

Nora, Pierre, (dir.), Les Lieux de Mémoire, París, Gallimard, 1997.

Orcástegui, Carmen y Sarasa, Esteban, La historia en la Edad Media, Madrid, Cátedra, 1991.

Pérez Garzón, Sisinio y Manzano Moreno, Eduardo, Memoria histórica, Madrid, Catarata, 2010.

Rischpler, Susanne, "Le coeur voyant. Mémoriser les Sentences de Pierre Lombard" en Willaert, Frank, Braet, Herman, Mertens, Thom and Venckleer, Theo, Medieval Memory. Image and Text, Turnhout, Brepols, 2004, págs. 3-41.

Red Internacional de historiadores "Historia a Debate" [en línea], disponible en http:// www.h-debate.com/Spanish/historia\%20inmediata/memoria/menu.htm [Consulta: 30 de septiembre de 2010]. 
Ricoeur, Paul, La memoria, la historia, el olvido, Madrid, Trotta, 2003.

Ruiz Domenech, Jose E., La memoria de los feudales, Barcelona, Argot, 1984.

Todorov, Tzvetan, La memoria, ¿un remedio contra el mal?, Barcelona, Arcadia, 2009.

Traverso, Enzo, El pasado, instrucciones de uso. Historia, memoria, política, Madrid, Marcial Pons, 2007.

Vilar, Pierre, Memoria, historia e historiadores, Valencia, Universidad de Valencia, 2004. 